\title{
Determination of Arsenic by Hydride Generation- Laser-Induced Breakdown Spectroscopy: Characterization of Interelement Interferences
}

\author{
Deniz Bölek, Semira Ünal Yeşiller, and Şerife Yalçın \\ Chemistry Department, Faculty of Science, İzmir Institute of Technology, İzmir, Turkey
}

\begin{abstract}
In this study, interelement interferences were evaluated for the determination of arsenic in aqueous samples through laser-induced breakdown spectroscopy (LIBS) hyphenated with a hydride generation sample introduction system. Optimum instrumental and chemical parameters were selected and variation in LIBS signal intensity was recorded for As solution in the presence of comparable concentrations of interfering elements. No significant change in the signal intensity of As(I) $228.8 \mathrm{~nm}$ line was observed in the presence of alkali/alkali earth metals; however, the presence of hydride-forming elements has shown a noticeable decrease in the line emission strength of arsenic. The least variation in arsenic signal was observed in the presence of $\mathrm{Ge}$, the most volatile of all. However, the signal has decreased to a greater extent in the presence of $\mathrm{Sn}, \mathrm{Sb}$, and $\mathrm{Pb}$. The presence of interfering elements on electron temperature and electron number density of arsenic plasma has also been studied. Plasma temperatures calculated using both As and Ar emission lines in the Boltzmann equation were similar, being around $5000 \mathrm{~K}$. The McWhirter criterion for stationary and homogenous plasmas was utilized for the establishment of the local thermodynamic equilibrium under the plasma conditions studied. Applicability of the technique for multielemental analysis of water samples was tested through spiking experiments. Arsenic signal showed $26 \%$ decrease in the multielemental mixture solution. LIBS is among a few atomic spectroscopic techniques that facilitate rapid and simultaneous multielemental analysis without extensive sample preparation steps. However, the analytical performance of the technique still requires more serious efforts to compete with other conventional techniques for routine analysis of environmental samples.
\end{abstract}

\section{ARTICLE HISTORY}

Received 16 August 2017

Accepted 23 September 2017

\section{KEYWORDS}

Arsenic; aqueous samples; hydride generation; laserinduced breakdown spectroscopy

\section{Introduction}

Due to its toxicity, arsenic (As) is among the most studied element with several uses in different fields from medicine to the military. The presence and concentration of this element in various matrices are mostly determined by common atomic spectroscopic techniques coupled with hydride generation sample introduction method such as atomic absorption spectrometry (AAS), atomic emission spectrometry, atomic fluorescence spectrometry, inductively coupled plasma-mass spectrometry (ICP-MS) and inductively 
coupled plasma-optical emission spectrometry (ICP-OES) (Pohl 2004; Bings, Bogaerts, and Broekaert 2012).

Hydride generation (HG) (Dedina and Tsalev 1995) is a chemical derivatization technique that allows formation and separation of volatile hydrides from other accompanying materials when they react with a strong reducing agent, (sodium borohydride, $\left.\mathrm{NaBH}_{4}\right)$ in the presence of hydrochloric acid $(\mathrm{HCl})$. With this technique, several elements in the periodic table, such as $\mathrm{As}, \mathrm{Sn}, \mathrm{Sb}, \mathrm{Se}, \mathrm{Ge}$, and $\mathrm{Pb}$, can be separated from the sample matrix and detected at trace and ultra-trace levels. However, the technique suffers from the interference effects in the presence of other elements in the matrix environment regardless of the type of the spectroscopic technique used for the detection. These interferences usually result in a decrease in analyte intensity and may occur either in the liquid phase (during chemical hydride generation process) or in the gas phase (in atomization process). Understanding the causes and the mechanism of interferences either in the reaction vessel or in atomization step is important and still an active area of research in atomic spectroscopy (Dittrich and Mandry 1986; D’ulivo, Lampugnani, and Zamboni 1991; Pohl and Zyrnicki 2002; Kumar and Riyazuddin 2010; Henden et al. 2011).

Liquid phase interferences (Dedina and Tsalev 1995) are mostly due to the presence of some transition metals in the sample that can affect the hydride generation efficiency of the system as a result of the interaction of the analyte hydride with reduced forms of the metals. A separate measurement of the amount of the analyte left in the waste solution, after hydrides are produced, may provide information about the residual (unreacted) analyte and hence the absolute hydride generation efficiency of the system. However, analyte losses during transportation of the volatile hydrides from the gas-liquid separator to the atomizer (through adsorption onto the walls of the tubing) is another source of error that results with reduced signal intensities. Gas phase interferences are still an active area of study in atomic spectroscopy and not yet understood. Gas phase interferences may occur due to transportation of matrix elements into the atomizer along with volatile hydrides of the analyte and also due to some reactions occurring inside the atomizer (e.g., formation of stable diatomic molecules) that necessitates the use of higher atomization temperatures for higher sensitivity (Dittrich and Mandry 1986). Typically, due to high atomization and excitation temperatures, gas phase interferences are not a significant problem in plasma type atomization systems.

Laser-induced breakdown spectroscopy (LIBS) (Cremers and Radziemski 2006; Miziolek, Palleschi, and Schechter 2006) has become increasingly popular due to its remarkable features like non-invasiveness, speed, portability and multi-element capability. While LIBS offers fast and real-time measurement easily for the analysis of solids, liquid sample analysis by LIBS still needs some special methodologies to be performed due to inherent drawbacks of the technique encountered. Plasma formation; on flowing jet liquids (Haisch et al. 1997; Kumar, Yueh, and Singh 2003; Feng et al. 2010; Faye et al. 2014), inside bubbles (Koch et al. 2006), on liquid droplets (Janzen et al. 2005; Cahoon and Almirall 2012), aerosol formation by nebulization (Radziemski et al. 1983; Aras et al. 2012) or by electro-spray ionization (Huang et al. 2002; Huang, Liu, and Lin 2007), changing the samples physical condition by freezing (Cáceres et al. 2001), absorbing the liquid on a solid substrate (Chen et al. 2008; Sarkar et al. 2010) and use of sequential laser pulses (Cremers, Radziemski, and Loree 1984; Pearman, Scaffidi, and Angel 2003; Rai, Yueh, and Singh 
2008; Lee et al. 2011; Rifai et al. 2012) are some of the efforts devoted to increase analytical capability of the LIBS technique in liquid analysis.

Recently, some studies based on hydride generation (HG) sample introduction coupled with LIBS detection, for the analysis of some hydride forming elements like As, $\mathrm{Sb}, \mathrm{Sn}, \mathrm{Pb}$, and Ge has been introduced (Simeonsson and Williamson 2011; Singh et al. 1996; Unal 2010; Yesiller and Yalçın 2013). Our group has previously reported optimum chemical and instrumental parameters for the determination of $\mathrm{Sn}$ (Unal 2010), As, Sb, Pb, Ge (Yeşiller and Yalçın 2013) in aqueous environments by HG-LIBS. A strong enhancement in signal strength and improvement in the limit of detection values of the studied elements, compared to direct analysis of bulk liquid samples by LIBS, was obtained. However, the inter-element interference effects were not investigated.

There are some LIBS studies in the literature related to the interference effect, on solid samples (Vrenegor, Noll, and Sturm 2005; Aguilera et al. 2009; Piscitelli S et al. 2009; Unnikrishnan et al. 2013); however, according to our knowledge, no direct application on investigating inter-element interference effect in liquid samples, especially with the HG sample introduction technique, is present. The performance of HG-LIBS for quantitative multielemental analysis has not been established yet and requires serious laboratory efforts.

In this study, the magnitude of inter-element interference effects on the LIBS signal intensity of As in the presence of (1) alkali/alkali earth metals ( $\mathrm{Na}, \mathrm{K}, \mathrm{Mg}, \mathrm{Ca}$ ), and (2) other hydride forming elements including $\mathrm{Pb}, \mathrm{Sn}, \mathrm{Sb}$, and $\mathrm{Ge}$ was evaluated for the first time. The hydride generation efficiency of the system for elements under consideration was determined by ICP-MS measurements. After careful selection of optimum instrumental and chemical parameters, variation in LIBS signal intensity was recorded for As solutions in the presence of interfering elements. Furthermore, the variation of electron temperature and electron number density in the presence of other hydride forming elements has been evaluated. The applicability of HG-LIBS technique for multi-element analysis was tested on synthetic water mixtures.

Laser-induced breakdown spectroscopy is still considered as an emerging technique but will soon play a dominant role in many fields for chemical analysis. Accurate determination of arsenic with an easy and fast analysis technique like LIBS is important due to the environmental significance of arsenic, as a highly toxic and worst polluting element of fresh waters worldwide. Present manuscript investigates for the first time the interference of hydride forming elements on determination of arsenic and is significant from the fundamental aspects in which the conditions, capabilities and limitations of the HG-LIBS technique are defined. Further research, development and engineering will increase the performance and applicability of the methodology.

\section{Materials and methods}

\section{Experimental}

The details of the experimental set-up for continuous flow HG-LIBS system has been given elsewhere (Ünal and Yalçın 2010; Yeşiller and Yalçın 2013). The system is comprised a hydride generation unit, a plasma cell, and a detection unit.

Chemically generated volatile hydrides from the hydride generation unit were transported into a five-armed Teflon plasma cell with a controlled flow of inert gas (Ar 
or $\mathrm{N}_{2}$ ). Laser pulses of 100-150 mJ energy, from a Q-switched Nd:YAG laser (Spectra Physics, LAB 170-10) operating at the second harmonic wavelength (532 nm) with $10 \mathrm{~ns}$ pulse width and $10 \mathrm{~Hz}$ pulse repetition rate, were focused in the center of a Teflon cell by a $17.5 \mathrm{~cm}$ focal length plano-convex lens to create the plasma.

Plasma emission was collected and focused using two $10 \mathrm{~cm}$ focal length plano-convex lenses onto the fiber optic cable (Ocean Optics, $600 \mu \mathrm{m}$ ). This fiber was then coupled to an echelle type spectrograph (ME5000, Andor Inc., $f=195 \mathrm{~mm}, 0.08 \mathrm{~nm}$ resolution), equipped with a gated, image intensified charge coupled detector, Intensified Charge Coupled Device (iStar DH734, Andor Inc.). Wavelength calibration of the spectrograph was performed using a $\mathrm{Hg}$-Ar lamp (Ocean Optics) and intensity calibration was performed by Deuterium-Tungsten-Halogen Calibration Standard (DH-2000-CAL, Ocean Optics). Detector gain was kept at a setting of 100 and 10 shot accumulation spectra were used for most of the measurements. The chemical and instrumental operating conditions optimized for observing maximum arsenic signal at $228 \mathrm{~nm}$ for single standard and multi-element samples are listed in Table 1.

The residual $\mathrm{As}, \mathrm{Sb}, \mathrm{Sn}, \mathrm{Ge}$, and $\mathrm{Pb}$ in the waste solutions of the HG system were determined by an Agilent 7500ce ICP-MS (Tokyo, Japan), equipped with a quartz concentric nebulizer, a Peltier-cooled spray chamber $\left(2^{\circ} \mathrm{C}\right)$, and an ASX-500 Series autosampler. The system was operated under $1550 \mathrm{~W}$ forward (RF) power, $0.100 \mathrm{~s}$ integration time, $0.310 \mathrm{~s}$ sampling period, $0.85 \mathrm{~L} \mathrm{~min}^{-1}$ carrier gas (Ar) and $0.16 \mathrm{~L} \mathrm{~min}^{-1}$ makeup gas. Isotope masses of analyzed elements were ${ }^{75} \mathrm{As},{ }^{121} \mathrm{Sb},{ }^{72} \mathrm{Ge},{ }^{208} \mathrm{~Pb}$, and ${ }^{118} \mathrm{Sn}$.

\section{Standards and reagents}

All solutions of $\mathrm{As}, \mathrm{Sb}, \mathrm{Ge}, \mathrm{Pb}$, and $\mathrm{Sn}$ were prepared fresh by appropriate dilutions of $1000 \mathrm{mg} \mathrm{L}^{-1}$ (High-Purity Standards) standard solutions with ultrapure water. All reagents were of analytical grade or higher purity. Standard and real samples were acidified with concentrated $\mathrm{HCl}$ to reach desired acid concentrations of $1 \%$ or $2 \%$ by volume. $0.5 \%$ sodium borohydride $\left(\mathrm{NaBH}_{4}\right)$ solution was prepared by dissolving an appropriate amount of the powder (Sigma-Aldrich, Turkey) in $0.2 \% \mathrm{NaOH}$ (Riedel-de Haën) for stabilization and used without filtration. Aqueous stock solutions $\left(1000 \mathrm{mg} \mathrm{L}^{-1}\right)$ of alkali/alkali earth metals ( $\mathrm{Na}, \mathrm{K}, \mathrm{Mg}, \mathrm{Ca}$ ) have been prepared by dissolving appropriate amounts of analytical grade solids from their chloride salts in ultrapure water. $0.5 \%$ L-cysteine and $2 \% \mathrm{~K}_{3}\left[\mathrm{Fe}(\mathrm{CN})_{6}\right]$ solutions were used as reducing and oxidizing agents for $\mathrm{Sb}$ and $\mathrm{Pb}$, respectively, in their single standards and in multielemental mixture solutions.

Table 1. Operating parameters for continuous flow HG-LIBS system.

\begin{tabular}{|c|c|c|}
\hline & Single standard & Multi element \\
\hline Laser energy ( $\mathrm{mJ}$ pulse $\left.{ }^{-1}\right)$ & 130 & 100 \\
\hline$T_{\mathrm{d}}(\mu \mathrm{s})$ & 1,3 & 4 \\
\hline$T_{\mathrm{g}}(\mu \mathrm{s})$ & 500,750 & 100 \\
\hline $\mathrm{NaBH}_{4}$ conc. (w/v\%) & 0.5 & 1 \\
\hline $\mathrm{NaBH}_{4}$ flow rate $\left(\mathrm{mL} \mathrm{min}^{-1}\right)$ & 5 & 5 \\
\hline $\mathrm{HCl}$ conc. (v/v\%) & 1 & 2 \\
\hline Sample flow rate $\left(\mathrm{mL} \mathrm{min}^{-1}\right)$ & 2.5 & 2.5 \\
\hline Pre-reducing/oxidizing agent ${ }^{*}$ & - & $0.5 \%$ I-Cysteine \\
\hline Concentration (w/v\%) & & $2 \% \mathrm{~K}_{3}\left[\mathrm{Fe}(\mathrm{CN})_{6}\right]$ \\
\hline Carrier gas flow rate $(\mathrm{Ar})\left(\mathrm{mL} \mathrm{min}^{-1}\right.$ & 126 & 126 \\
\hline
\end{tabular}




\section{Results and discussion}

This section comprises four parts. In the first part, hydride generation efficiency of the system is presented. In the second part, the effect of presence of interfering elements (alkali/alkaline earth elements and other hydride forming elements) on arsenic signal intensity is investigated. In the third part, the variation in electron temperature and electron number density of arsenic hydride plasmas in the presence of interfering elements are determined. And, in the last part, the magnitude of inter-element interference from the presence of other hydride forming elements ( $\mathrm{Sn}, \mathrm{Ge}, \mathrm{Sb}$ and $\mathrm{Pb}$ ) in synthetic water mixtures is evaluated.

\section{Hydride generation efficiency of the system}

To determine the efficiency of a hydride generation system, a method based on the determination of the residual (unreacted) amount of the analyte in the post-reaction solution through independent measurements was performed. For this purpose, a series of As solutions were spiked with $\mathrm{Sn}, \mathrm{Ge}, \mathrm{Sb}$, and $\mathrm{Pb}$ solutions, separately, to reach final As and interfering element concentration of 20 and $30 \mathrm{mg} \mathrm{L}^{-1}$, respectively. Another sample of As solution that contains a mixture of all interfering elements was also prepared. Each of these five solutions was run through the HG-LIBS system, and post reaction solutions (waste) were collected. The concentrations of As and other interfering elements in the waste solutions were determined through ICP-MS measurements. The hydride generation efficiency of the system for arsenic and for other interfering elements in the absence and presence of each interfering element separately and in the mixture is given in Table 2. The results of the measurements are given in terms of percent hydride generation efficiency of each element.

As can be seen from the first column in Table 2, 99.6\% conversion efficiency was obtained from a solution that contains arsenic only. The addition of $\mathrm{Sn}, \mathrm{Sb}$, and $\mathrm{Pb}$ on arsenic did not have much positive effect on the conversion efficiency of As, being 99.7, 99.7, and 99.2\%, respectively, indicating that the hydride generation reaction is highly efficient. The conversion efficiency of As in the presence of Ge was $94 \%$, while the conversion efficiency of $\mathrm{Ge}$ into its hydrides, in the same solution, was more complete being as $99.9 \%$.

In accordance with the order of volatility of their hydrides: $\mathrm{Ge}>\mathrm{As}>\mathrm{Sn}>\mathrm{Sb}>\mathrm{Pb}>$ (Dedina and Tsalev 1995), arsenic conversion efficiency is more affected in the presence of a more volatile hydride, $\mathrm{Ge}$, and is less affected by the presence of less volatile elements. The hydride generation efficiency of each element determined in the waste of a multielemental mixture solution is given in the last column of Table 2. The purpose of this study is to investigate the effect of the presence of other hydride forming elements in the determination of arsenic; therefore, in all samples, chemical hydride generation parameters (acid,

Table 2. Hydride generation efficiency of the HG-LIBS system determined for each element through ICP-MS measurements.

\begin{tabular}{lccc} 
& \multicolumn{3}{c}{ Hydride generation efficiency (\%) } \\
\cline { 2 - 4 } & As in the presence of $\mathrm{X}$ & $\mathrm{X}$ in the presence of As & $\mathrm{X}$ in the mixture \\
\hline $\mathrm{X}=\mathrm{As}$ & 99.6 & 99.6 & 99.6 \\
$\mathrm{X}=\mathrm{Sn}$ & 99.7 & 87.4 & 95.0 \\
$\mathrm{X}=\mathrm{Ge}$ & 94.0 & 99.9 & 99.9 \\
$\mathrm{X}=\mathrm{Sb}$ & 99.7 & 77.6 & 74.7 \\
$\mathrm{X}=\mathrm{Pb}$ & 99.2 & 88.8 & 81.3 \\
\hline
\end{tabular}


$\mathrm{NaBH}_{4}$ concentration, flow rates) optimized for maximum arsenic signal were used. High conversion efficiencies of 99.6, 95.0, and 99.9\% were obtained for As, Sn, and Ge, respectively, however, relatively lower conversion efficiencies were obtained for $\mathrm{Sb}$ $(74.7 \%)$ and for $\mathrm{Pb}(81.3 \%)$. This may be attributed to the absence of the pre-reducing agent, L-cysteine, for antimony and the oxidizing agent, potassium hexacyanoferrate(III), for $\mathrm{Pb}$ in the mixture solution; these would otherwise be added to obtain maximum sensitivity from these elements.

Inductively coupled plasma results generally indicate that, under the experimental conditions used, arsenic and other hydride forming elements were quantitatively transferred into their volatile hydrides and carried into the sample cell for plasma formation. The presence of other hydride forming elements at concentrations comparable to arsenic has no significant effect on the generation of volatile arsenic hydrides. Therefore, any change that may be observed in LIBS signal intensity of arsenic in the presence of those elements in laser-induced plasma may not be attributable to the inefficiency of the hydride generation system and its chemical conditions but instead chemical and physical processes that occur in hydrides plasma.

\section{Presence of interfering elements on LIBS signal intensity}

\section{Effect of presence of alkali/alkali earth metals on As signal intensity}

To investigate the presence of alkali/alkali earth metals, namely $\mathrm{Na}, \mathrm{K}, \mathrm{Ca}$, and $\mathrm{Mg}$ on arsenic signal intensity, initially, optimization of instrumental LIBS parameters (gate delay, gate width, laser pulse energy), and chemical hydride generation parameters (acid and reductant concentration, sample, and carrier gas flow rate) was performed. The details of optimization process for HG-LIBS systems have been given previously (Ünal and Yalçın 2010; Yeşiller and Yalçın 2013); therefore, only optimal conditions used throughout this study for maximum arsenic signal is listed in Table 1.

Then the effect of the presence of $\mathrm{Na}, \mathrm{K}, \mathrm{Ca}$, and $\mathrm{Mg}$ on arsenic signal intensity was studied through a series of measurements at several interfering element concentrations that are comparable to that of arsenic. For this purpose, $25 \mathrm{~mL}$ aliquots of $10 \mathrm{mg} \mathrm{L}^{-1}$ arsenic solutions were spiked with $1000 \mathrm{mg} \mathrm{L}^{-1}$ desired metal standard solution to reach final interfering element concentrations of $2,5,10,15$, and $20 \mathrm{mg} \mathrm{L}^{-1}$. These solutions were then subjected to HG-LIBS analysis for the measurement of arsenic signal.

The variation in the relative signal strength of neutral As(I) line at $228.81 \mathrm{~nm}$ with respect to various metal concentrations is given in Figure 1. For each element in the figure, the first bar corresponds arsenic signal intensity measured from the solution in which no interfering element present and the remaining bars, from left to right, correspond to arsenic signal in the presence of $2,5,10,15$, and $20 \mathrm{mg} \mathrm{L}^{-1}$ interfering element. As can be seen from the figure that, there are some variations in signal strength of arsenic with respect to varying concentrations of each element. However, these variations are within the standard error of the measurements and no significant changes in signal intensity of As(I) $228.8 \mathrm{~nm}$ line were observed in the presence of $\mathrm{Na}, \mathrm{K}, \mathrm{Ca}$, and $\mathrm{Mg}$ elements of between 2 and $20 \mathrm{mg} \mathrm{L}^{-1}$ concentrations. This observation, albeit a property of hydride generation technique in which only gaseous hydrides are introduced to the sample cell for atomization and the sample matrix is left in the liquid waste, shows the insensitivity of HG-LIBS technique to the other accompanying materials in the sample. 


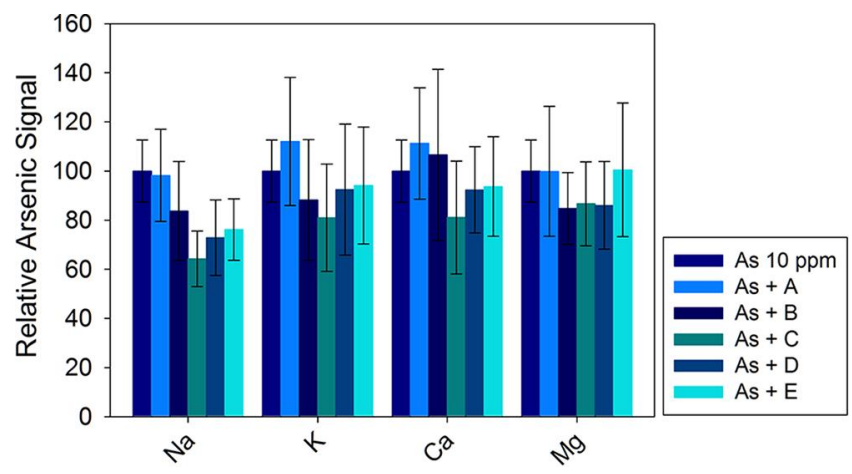

Figure 1. The effect of $\mathrm{Na}, \mathrm{K}, \mathrm{Ca}$, and $\mathrm{Mg}$ on the $10 \mathrm{mg} \mathrm{L}^{-1}$ As signal intensity. The left-most dark black bars represent arsenic signal from the solution with no interfering element present and the remaining bars, from left to right, correspond to arsenic signal in the presence of $2,5,10,15$, and $20 \mathrm{mg} \mathrm{L}^{-1}$ interfering element. Conditions: $126 \mathrm{~mL} \mathrm{~min}^{-1}$ Ar gas flow, detector delay time of $3 \mu \mathrm{s}$, detector gate time of $750 \mu \mathrm{s}, 130 \mathrm{~mJ}$ pulse ${ }^{-1}$ laser energy, and 10 repetitive sampling.

\section{Effect of hydride forming elements on As signal intensity}

To observe the effect of the presence of other hydride forming elements on arsenic signal strength, $20 \mathrm{mg} \mathrm{L}^{-1}$ concentrations of As solutions were spiked with $\mathrm{Sn}, \mathrm{Ge}, \mathrm{Sb}$, and $\mathrm{Pb}$ standard solutions to reach final interfering element concentrations of $1,2,5,10,20,30$, 40 , and $50 \mathrm{mg} \mathrm{L}^{-1}$. Each solution was run through the HG-LIBS system and spectra were analyzed for arsenic signal at $228.81 \mathrm{~nm}$. Figure 2 represents the variation of As signal as a function of interfering element concentration.

In general, arsenic signal decreases as interfering element concentration increases. This decrease is more serious in the presence of $\mathrm{Sn}, \mathrm{Sb}$, and $\mathrm{Pb}$ than in the presence of Ge. According to the results presented in Table 2, conversion of arsenic into its hydrides in the presence of other hydride forming elements is minimum $94 \%$ efficient. Therefore, this

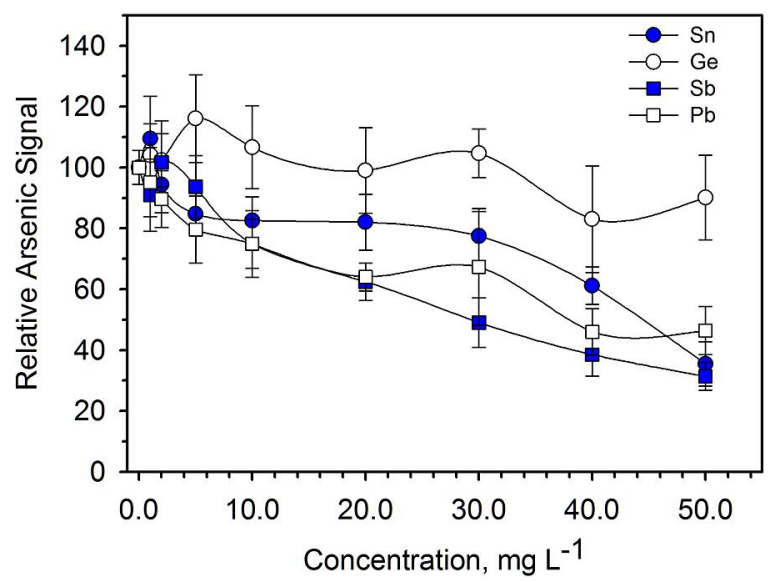

Figure 2. As signal intensity variation as a function of interfering element concentration for $\mathrm{Sn}, \mathrm{Ge}, \mathrm{Sb}$, and $\mathrm{Pb}$. Arsenic solution concentrations of $20 \mathrm{mg} \mathrm{L}^{-1}$ and interfering element concentrations between 1 and $50 \mathrm{mg} \mathrm{L}^{-1}$ were used. Conditions: detector delay time $3 \mu \mathrm{s}$, detector gate time $750 \mu \mathrm{s}, 130 \mathrm{~mJ}$ pulse $^{-1}$ laser energy, and 10 repetitive sampling. 
decrease may not be attributed to the liquid phase interference effect. However, poor stability and easy decomposition are well known properties of metal hydrides. Therefore, analyte loss by adsorption after being reduced to elemental form is highly probable. Signal suppression with increasing interfering element concentration may be due to the deposition of metal hydrides, after being reduced to elemental form, onto surfaces of the transport tubing. Careful examination of inner surfaces of the teflon tubing, after running HG-LIBS system for some period of time, a black deposit at a region where gas-liquid separator connected to the plasma cell has been observed. LIBS analysis of this black deposit inside the tubing revealed the presence of arsenic. Similar observation have been reported in the literature (Singh et al. 1996; Zheng, Sturgeon, and Hou 2010) for atomic absorption and LIBS systems that utilize HG-sample introduction method.

Gas phase interferences have been widely observed in AAS systems due to the formation of diatomic molecules (like $\mathrm{AsSb}, \mathrm{Sb}_{2}$ ) inside the atomizer that lead to signal suppression and necessitates the use of higher atomization temperatures. Dittrich and Mandry (1986) suggested the use of graphite furnace atomizer having a temperature higher than $2000^{\circ} \mathrm{C}$ to dissociate diatomic AsSb molecules and reduce the magnitude of the gas-phase interferences. However, in laser-induced plasmas, since the sample cell is not being heated, the deposits due to diatomic molecule formation neither inside the tubing nor on the walls of a sample cell are removed. High electron number densities $\left(10^{17}\right)$ and around $10,000 \mathrm{~K}$ electron temperatures attained in laser produced plasmas exist only at the point where laser beam is focussed.

\section{Plasma electron temperature and electron number density calculations}

Electron temperature and electron number density are the two important parameters for the characterization of the state of the laser-induced plasmas if local thermodynamic equilibrium (LTE) condition exists. LTE is a theoretical concept that can never be exactly met (Fujimoto and McWhirter 1990). However, there are some assumptions used by the plasma scientists to validate the existence of LTE. The most popular one for assessing the validity of the LTE assumption is the McWhirter criterion (Cristoforetti et al. 2010), in which the minimum electron number density needs to be present for the existence of LTE is determined.

In this approach, if electron number density calculated according to McWhirter criterion is lower than experimentally measured one (mostly obtained from Stark Broadening), then local thermodynamic equilibrium conditions are said to be satisfied. For the stationary and homogeneous plasmas where problems related to spatial gradients and time variations are not considered, the McWhirter criterion is expressed by a simple relationship given below (Cristoforetti et al. 2010):

$$
N_{\mathrm{e}}>1.6 \times 10^{12}(T)^{\frac{1}{2}}(E)^{3} \mathrm{~cm}^{-3}
$$

where $T$ and $\Delta E$ are the temperature and energy difference between the ground level and the first excited level and expressed in $\mathrm{K}$ and $\mathrm{eV}$, respectively. Once the experimental values of temperature and electron number density are known, the fulfillment of the LTE can be easily judged. However, it is essential to know that, the McWhirter criterion is applicable to homogeneous and stationary plasmas and it is necessary but not sufficient condition to ensure LTE. There are a large number of publications in the literature on the determination 
of electron temperature, electron number density and the existence of LTE for laserproduced plasmas (Sabsabi and Cielo 1995; Knight et al. 2000; Barthelemy et al. 2005; Aragón and Aguilera 2008).

In this study, the electron temperature of arsenic hydride plasmas in the presence of interfering elements (alkali/alkali earth metals and other hydride forming elements) were evaluated using a well-known Boltzmann method (Griem 1964). For this purpose, spectral emission intensities of arsenic and argon lines that could be identified within the spectral range of the spectrograph were utilized. Some spectroscopic constants of the atomic emission lines used in the calculations of the temperature and electron density of the arsenic hydride plasmas were taken from NIST database and Griem' well-known books (Griem 1964, 1974).

Electron number density $\left(N_{\mathrm{e}}\right)$ of arsenic hydride plasmas was determined from the measurement of widths of Stark-broadened $H_{\alpha}$ line at $656.3 \mathrm{~nm}$ and by the equation given below (Griem 1974; El Sherbini, Hegazy, and El Sherbini 2006):

$$
N_{\mathrm{e}}\left(H_{\alpha}\right)=8.02 \times 10^{12}\left(\frac{\Delta \lambda_{\frac{1}{2}}}{\alpha_{\frac{1}{2}}}\right)^{\frac{3}{2}} \mathrm{~cm}^{-3}
$$

where $\alpha_{1 / 2}$, the half width of the reduced Stark profiles in $\AA$, is tabulated for the emission lines of the hydrogen at some typical temperatures (Griem 1974) and $\Delta \lambda_{1 / 2}$ is the width parameter value found by fitting the $H_{\alpha}$ peak to Lorentzian profile. Experimentally observed line width also consists of the instrumental width and should be corrected. The instrumental width of the spectrograph depends on slit widths, the grating dispersion and the dynamic behavior of the photon detector (Samek et al. 2000). Calculated total line width is given by the following formula:

$$
\Delta \lambda_{\text {total }}=\Delta \lambda_{\text {line }}+\Delta \lambda_{\text {spectrometer }}
$$

To find the instrumental broadening $\left(\Delta \lambda_{\text {spectrometer }}\right)$ parameter, the emission line from $\mathrm{Hg}$-Ar lamp at $253.7 \mathrm{~nm}$ was used. This line exhibited a Gaussian line profile with a full width at half maximum value of $0.52 \AA$ and was subtracted from the observed line width $\left(\Delta \lambda_{\text {total }}\right)$ to obtain $\Delta \lambda_{1 / 2}$.

\section{Electron temperature of the arsenic hydride plasmas in the presence of alkali/alkali earth metals and other hydride forming elements}

Plasma electron temperature variation in the presence of varying concentrations of alkali/ alkali earth metals and hydride forming elements calculated by the Boltzmann method using both arsenic and argon emission lines are shown in Figure 3. For each element, the first bar represents the temperature from the arsenic solution with no interfering element present and the remaining bars, from left to right, correspond to temperatures in the presence of varying concentrations of alkali metal and hydride forming elements, respectively.

Figure $3 \mathrm{a}$ and $\mathrm{b}$ represent temperature variation calculated using arsenic and argon emission lines, respectively, in the presence of 2, 5, 10, 15, and $20 \mathrm{mg} \mathrm{L}^{-1}$ alkali/alkali earth elements. Here, the temperatures calculated from As lines and from Ar lines are very similar, being around $5000 \mathrm{~K}$ at the specified delay time of the experiment. To better 

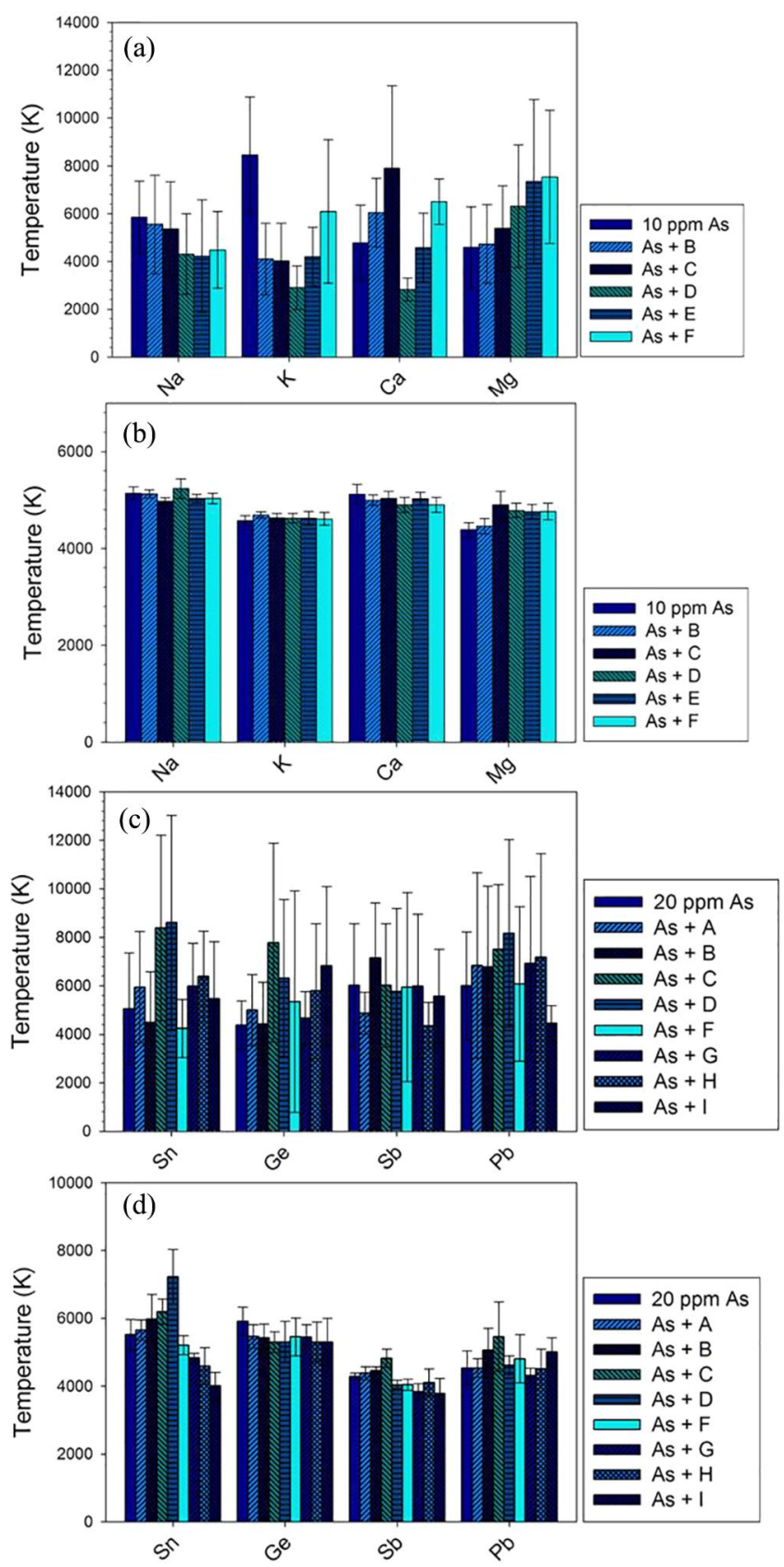

Figure 3. Plasma electron temperatures calculated in the presence of different concentrations of (a) alkali/alkaline earth metals using $10 \mathrm{mg} \mathrm{L}^{-1}$ arsenic emission lines, (b) alkali/alkaline earth metals using argon emission lines, (c) other hydride forming elements using $20 \mathrm{mg} \mathrm{L}^{-1}$ arsenic emission lines, and (d) other hydride forming elements using argon emission lines, in the Boltzmann equation. The interfering element concentrations were (A) 1, (B) 2, (C) 5, (D) 10, (E) 15, (F) 20, (G) 30, (H) 40, and (I) $50 \mathrm{mg} \mathrm{L}^{-1}$ added to the arsenic solution. Measurements were performed using the optimum operating parameters listed in Table 1. 
understand that this agreement of the temperatures from As and Ar lines may indicate the existence of LTE conditions, McWhirter criterion for homogeneous plasmas was applied after electron number density measurements were performed.

As is shown in Figure 3a, electron temperatures obtained using arsenic emission lines present a higher degree of standard deviation (maximum $40 \%$ relative standard deviation) than temperatures obtained using Ar lines, (10\% relative standard deviation). This observation can be attributed to the number of emission lines available in Boltzmann equation. It is known that measuring temperature through Boltzmann plot is very sensitive to the choice and accuracy of the spectral parameters as well as the availability of the number of spectral emission lines. In this case, there were only two arsenic emission lines to be used in Boltzmann plot which is not sufficient to construct a reliable Boltzmann plot. We think that such large errors are mainly due to insufficient number of spectral lines rather than the accuracy of the spectroscopic constants. In general, considering the behavior observed in Figure $3 \mathrm{~b}$, one may conclude that none of the metals $(\mathrm{Na}, \mathrm{K}, \mathrm{Ca}$, and $\mathrm{Mg}$ ) added to an arsenic solution make a significant change in temperatures of arsenic hydride plasmas.

Figure $3 \mathrm{c}$ and $\mathrm{d}$ represent temperature variation calculated using arsenic and argon emission lines, respectively, in the presence of $1,2,5,10,20,30,40$, and $50 \mathrm{mg} \mathrm{L}^{-1}$ hydride forming elements, $\mathrm{Sn}, \mathrm{Ge}, \mathrm{Sb}$ and $\mathrm{Pb}$, in the presence of arsenic. The temperature values obtained using arsenic emission lines, as shown in Figure $3 c$, exhibit little variation by the addition of hydride-forming elements and agree well within experimental error. The relative standard deviation of the temperatures using arsenic lines is relatively higher than of the temperatures calculated using argon lines. Also, as is shown in Figure $3 \mathrm{~d}$, arsenic hydride plasmas in the presence of $\mathrm{Sn}$ and $\mathrm{Ge}$ produce relatively higher temperatures (approximately 15-20\% more) compared to the ones obtained in the presence of less volatile ones $(\mathrm{Sb}$ and $\mathrm{Pb})$. The results show that there is a small variation in plasma temperatures of arsenic hydrides in the presence of hydride forming elements for both temperature sensors, As and Ar.

\section{Electron number density, $N_{\mathrm{e}}$, of arsenic hydride plasmas in the presence of alkali/ alkali earth metals and other hydride forming elements}

Electron number density variation of arsenic hydride plasmas with respect to varying concentrations of alkali metals is shown in Figure $4 \mathrm{a}$. In the absence of alkali/alkali earth metals, plasma electron number density was calculated to be $0.7 \times 10^{17} \mathrm{~cm}^{-3}$ and is shown as the first bar, for each element, in Figure 4a. For the alkali metal added cases, electron number density does not change much with respect to varying concentrations of $\mathrm{Na}$ and $\mathrm{K}$, and stays within the standard error of the measurements. However, with increasing $\mathrm{Ca}$ and $\mathrm{Mg}$ concentrations, electron number density exhibits a little increase.

Electron number density variation of arsenic hydride plasmas in the presence of varying concentrations of (1-50 mg L $\left.\mathrm{m}^{-1}\right)$ hydride forming elements is shown in Figure $4 \mathrm{~b}$. Except for the anomalous behavior observed for Sn, plasma electron density values do not show a noticeable change in the presence of different types and concentrations of interfering elements, $\mathrm{Ge}, \mathrm{Sb}$ and $\mathrm{Pb}$. Among them, presence of $\mathrm{Ge}$ shows an observable change with respect to changing Ge concentrations. This insensitivity of arsenic hydride plasma temperatures and electron number densities to the type and extent of interfering element concentrations is promising for the quantitative use of HG-LIBS approach. 

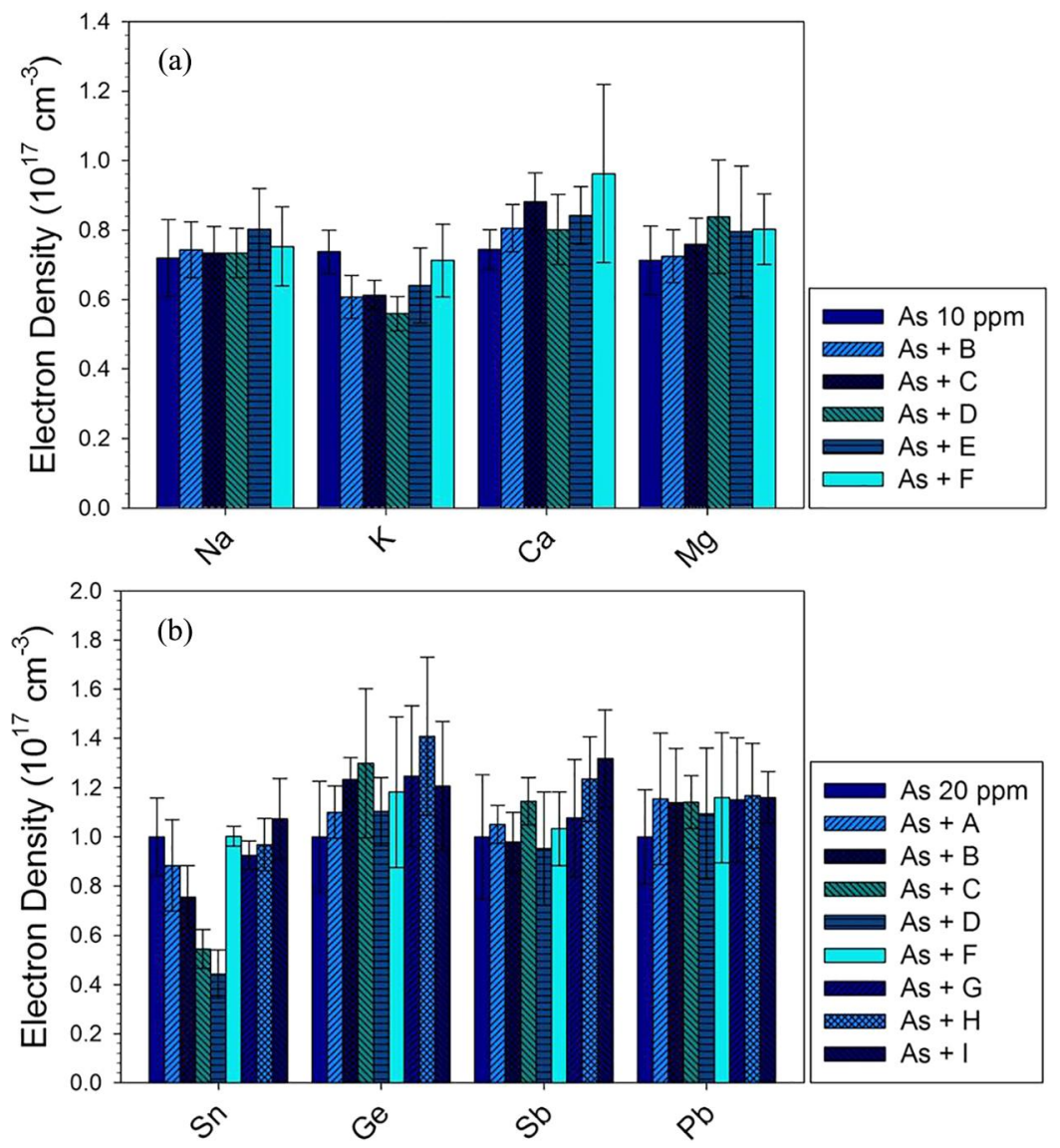

Figure 4. Electron number density variation of As hydride plasmas in the presence of different concentrations of (a) alkali and alkaline earth metals and (b) other hydride forming elements. Interfering element concentrations of (A) 1, (B) 2, (C) 5, (D) 10, (E) 15, (F) 20, (G) 30, (H) 40, and (I) $50 \mathrm{mg} \mathrm{L}^{-1}$ were added to the arsenic solution. Measurements were performed using the optimum operating parameters listed in Table 1.

Once the temperature and electron number density of the arsenic hydride plasmas were roughly estimated, it is possible to evaluate the existence of the LTE condition. According to McWhirter criterion, incorporating an average temperature of T: $5000 \mathrm{~K}$, and As(I) $228.8 \mathrm{~nm}$ level energy of $\Delta E=6.7 \mathrm{eV}$ into Eq. (1), one can obtain electron number density of $N_{\mathrm{e}}=3.4 \times 10^{16} \mathrm{~cm}^{-3}$. This value is lower than the experimentally measured electron number density values of arsenic hydride plasmas both in the presence of alkali/alkali earth metals and other hydride forming elements, being as $7 \times 10^{16}$ and $1 \times 10^{17} \mathrm{~cm}^{-3}$, respectively. As a rough estimation, the possibility of the existence of the local thermodynamic equilibrium conditions in arsenic hydride plasmas can be granted.

\section{Applications to multielemental analysis}

To investigate the applicability of the HG-LIBS method for multi-element analysis of water samples, ultrapure water samples were spiked with $1000 \mathrm{mg} \mathrm{L}^{-1}$ single standard solutions of 
As, $\mathrm{Sn}, \mathrm{Sb}, \mathrm{Pb}$, and $\mathrm{Ge}$ to reach final element concentrations of $20 \mathrm{mg} \mathrm{L}^{-1}$ for each. This multi-element mixture solution was then analyzed by HG-LIBS method. Spectra were recorded under compromising conditions of $1 \% \mathrm{NaBH}_{4}$ in $0.2 \% \mathrm{NaOH}, 100 \mathrm{~mJ}$ pulse ${ }^{-1}$ laser energy, $4 \mu$ s delay time and $100 \mu$ sate width. Single standard solutions of each element were also prepared and analyzed in the same manner for comparison. $2 \% \mathrm{~K}_{3}(\mathrm{FeCN})_{6}$ as an oxidizing agent for lead and $0.5 \% \mathrm{~L}$-cysteine as a reducing agent for antimony were added into both standard and multi-element mixture solutions (Yeşiller and Yalçın 2013).

Hydride generation sample introduction coupled with laser-induced breakdown spectra recorded for single standard and synthetic multi-element mixture solution are shown in Figure 5. The bottom is the full range spectrum of multielemental mixture solution, in which highly intense hydrogen line $\left(H_{\alpha}\right)$ at $656.3 \mathrm{~nm}$ is observed in addition to $H_{\beta}$ $(486.1 \mathrm{~nm}), \mathrm{N}(\mathrm{I}) \quad(742.4,744.2,746.8 \mathrm{~nm}), \mathrm{O}(\mathrm{I})(777.4,822.1,844.6 \mathrm{~nm})$, and $\mathrm{Na}(\mathrm{I})$ $(589.0,589.6 \mathrm{~nm})$ emission lines. Above the full spectra in Figure 5, emission profiles of the hydride forming elements in single standard and in multielemental mixture are enlarged. It appears that each element is subject to varying degrees of interelement interferences. Percent decrease in signal strength of each element in the synthetic mixture solution, relative to the ones in single standard solution, was quantified from the peak area measurements and are given in Table 3. It is observed that As signal exhibited 26\% decrease in

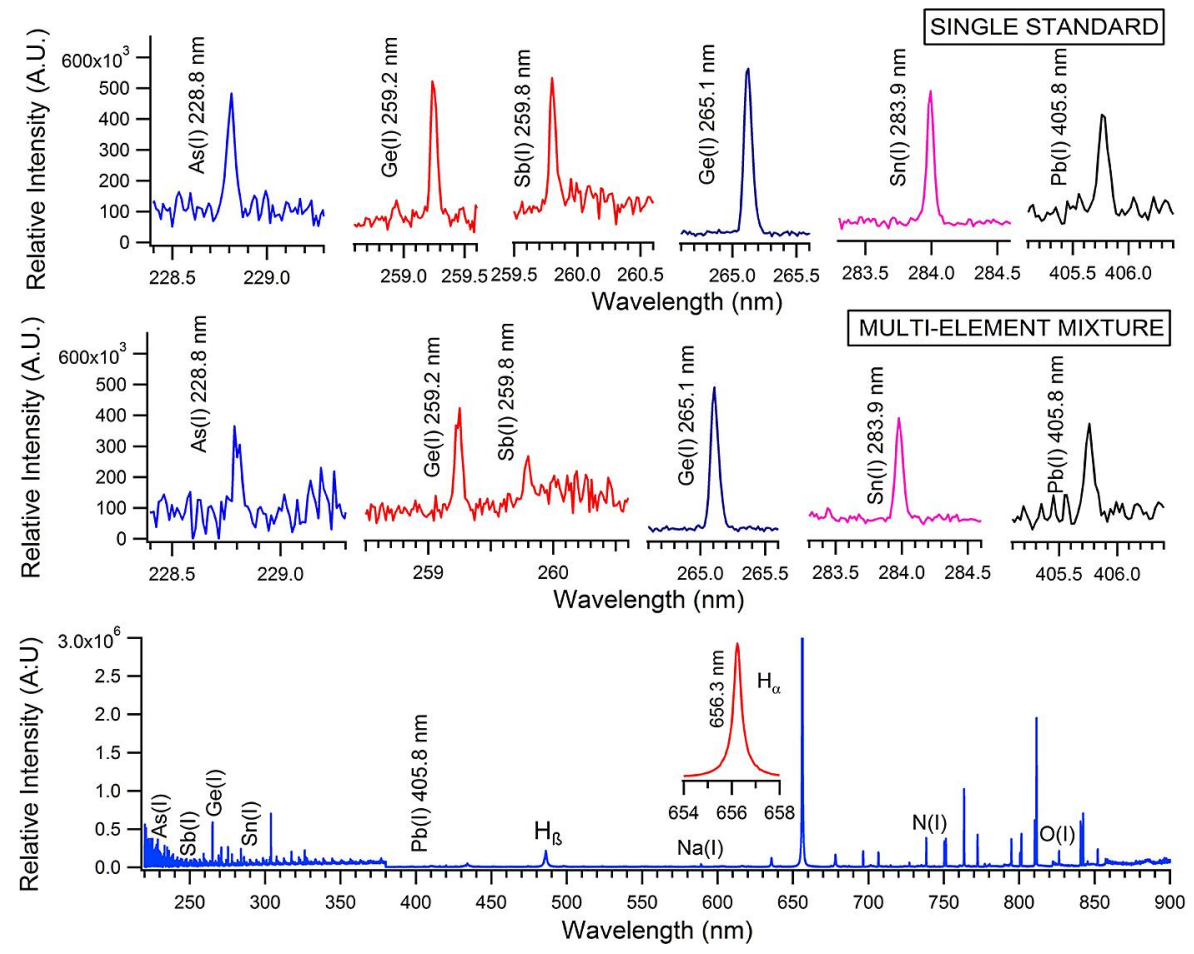

Figure 5. HG-LIBS spectral emission lines of hydride forming elements in single standard and synthetic multi-element mixture. Below is the full LIBS spectra in the $220-900 \mathrm{~nm}$ region. $H$ (I) $656.15 \mathrm{~nm}$ line profile is given enlarged. Arsenic and interfering element concentrations are $20 \mathrm{mg} \mathrm{L}^{-1}$. Spectra were recorded under compromise conditions of $1 \% \mathrm{NaBH}_{4}$ in $0.2 \% \mathrm{NaOH}, 100 \mathrm{~mJ}$ pulse ${ }^{-1}$ laser energy, $4 \mu \mathrm{s}$ delay time and $100 \mu \mathrm{s}$ gate width. Note: LIBS, laser-induced breakdown spectroscopy. 
Table 3. Percent decrease in signal intensity relative to single standard solution.

\begin{tabular}{cccccc}
\hline & $\mathrm{As}(\mathrm{I}) 228.8 \mathrm{~nm}$ & $\mathrm{~Pb}(\mathrm{I}) 405.8 \mathrm{~nm}$ & $\mathrm{Ge}(\mathrm{I}) 265.1 \mathrm{~nm}$ & $\mathrm{Sn}$ (I) $283.9 \mathrm{~nm}$ & $\mathrm{Sb}$ (I) $259.8 \mathrm{~nm}$ \\
\hline $\begin{array}{c}\text { Decrease in signal } \\
\text { intensity (\%) }\end{array}$ & $26 \pm 21.8$ & $10 \pm 19.2$ & $21 \pm 37.2$ & $19 \pm 23.3$ & $46 \pm 24.4$ \\
\hline
\end{tabular}

signal strength in the presence of $\mathrm{Ge}, \mathrm{Sb}, \mathrm{Sn}$ and $\mathrm{Pb}$ mixture. Percent decreases in emission intensity of $\mathrm{Pb}, \mathrm{Ge}, \mathrm{Sn}$, and $\mathrm{Sb}$ were estimated as $10,21,19$, and $46 \%$, respectively.

\section{Conclusion}

In this study, the magnitude of interelemental interference effects on LIBS signal intensity of As, in the presence of alkali/alkaline earth metals ( $\mathrm{Na}, \mathrm{K}, \mathrm{Mg}, \mathrm{Ca}$ ) and other hydride forming elements ( $\mathrm{Sn}, \mathrm{Sb}, \mathrm{Pb}$, and $\mathrm{Ge}$ ), were evaluated. The hydride generation efficiency of the system for each element has been determined through ICP-MS measurements. It has been found that arsenic is minimum $94 \%$ efficient in the presence of other hydride forming elements, indicating the existence of liquid phase interferences to the lowest extent under the chemical conditions used.

After careful selection of optimum instrumental and chemical parameters, the variation in LIBS signal intensity was recorded for $10 \mu \mathrm{g} \mathrm{mL}^{-1}$ of As solutions in the presence of interfering elements of between 1 and $20 \mu \mathrm{g} \mathrm{mL}^{-1}$ concentrations. No significant change in signal intensity of $\mathrm{As}(\mathrm{I}) 228.8 \mathrm{~nm}$ line was observed in the presence of alkali/alkaline earth metals. Electron temperature and electron number density variation with respect to varying concentrations of alkali metals also stay within the standard error of the measurements.

Presence of other hydride forming elements ( $\mathrm{Sn}, \mathrm{Ge}, \mathrm{Sb}$, and $\mathrm{Pb}$ ) in $10 \mu \mathrm{g} \mathrm{mL}^{-1} \mathrm{As}$ solution have shown a noticeable decrease in signal intensity of As. However, the variation of electron temperature and electron number density of arsenic hydride plasmas in the presence of other hydride forming elements is not significant. The existence of local thermodynamic equilibrium conditions in HG-LIBS plasmas was tested according to McWhirter criterion and local thermodynamic equilibrium conditions are granted. The technique was applied to water samples for multielemental analysis and $26 \%$ suppression in As signal was observed in the presence of other hydride forming elements.

The observed insensitivity of arsenic hydride plasma temperatures and electron number densities to the type and extent of interfering element concentrations is promising for the use of the HG-LIBS approach for quantitative analysis of aqueous samples. However, more detailed research is required to improve analytical performance of the technique for rapid, field-based multielemental analysis for environmental purposes.

\section{Funding}

The authors thank the İzmir Institute of Technology, IYTE and the Scientific and Technological Research Council of Turkey, TÜBİTAK, for their financial support through research projects IYTE-BAP and 109T327.

\section{References}

Aragón, C. and J. A. Aguilera. 2008. Characterization of laser induced plasmas by optical emission spectroscopy: A review of experiments and methods. Spectrochimica Acta Part B 63 (9):893-916. 
Aguilera, J., C. Aragón, V. Madurga, and J. Manrique. 2009. Study of matrix effects in laser induced breakdown spectroscopy on metallic samples using plasma characterization by emission spectroscopy. Spectrochimica Acta Part B 64 (10):993-8.

Aras, N., S. U. Yesiller, D. A. Ates, and S. Yalcin. 2012. Ultrasonic nebulization-sample introduction system for quantitative analysis of liquid samples by laser-induced breakdown spectroscopy. Spectrochimica Acta Part B 74-75:87-94.

Barthelemy, O., J. Margot, S. Laville, F. Vidal, M. Chaker, B. Le Drogoff, T. W. Johnston, M. Sabsabi, 2005. Investigation of the state of local thermodynamic equilibrium of a laser-produced aluminium plasma. Applied Spectroscopy 59:529-36.

Bings, N. H., A. Bogaerts and J. A. Broekaert. 2012. Atomic spectroscopy. Analytical Chemistry 85 (2):670-704.

Cremers, D. A., L. J. Radziemski and T. R. Loree. 1984. Spectrochemical analysis of liquids using the laser spark. Applied Spectroscopy 38 (5):721-9.

Cáceres, J., J. Tornero López, H. Telle, and A. Gonzalez Urena. 2001. Quantitative analysis of trace metal ions in ice using laser-induced breakdown spectroscopy. Spectrochimica Acta Part B $56(6): 831-38$

Cremers, D. A. and L. J. Radziemski. 2006. Handbook of laser-induced breakdown spectroscopy. England: Wiley.

Chen, Z., H. Li, M. Liu, and R. Li. 2008. Fast and sensitive trace metal analysis in aqueous solutions by laser-induced breakdown spectroscopy using wood slice substrates. Spectrochimica Acta Part B 63 (1):64-68.

Cristoforetti, G., A. DeGiacomo, M. Dell'Aglio, S. Legnaioli, E. Tognoni, V. Palleschi, and N. Omenetto. 2010. Local thermodynamic equilibrium in laser-induced breakdown spectroscopy: Beyond the McWhirter criterion. Spectrochimica Acta Part B 65 (1):86-95.

Cahoon, E. M. and J. R. Almirall. 2012. Quantitative analysis of liquids from aerosols and microdrops using laser induced breakdown spectroscopy. Analytical Chemistry 84 (5):2239-44.

Dittrich, K. and R. Mandry. 1986. Investigations into the improvement of the analytical application of the hydride technique in atomic absorption spectrometry by matrix modification and graphite furnace atomisation. Part I. Analytical results. Analyst 111 (3):269-75.

D’ulivo, A., L. Lampugnani, and R. Zamboni. 1991. Interference of copper, silver and gold in the determination of selenium by hydride generation atomic fluorescence spectrometry: An approach to the studies of transition metal interferences. Journal of Analytical Atomic Spectrometry 6 (7):565-71.

Dedina, J. and D. L. Tsalev. 1995. Hydride generation atomic absorption spectrometry. England: John Wiley \& Sons.

El Sherbini, A., H. Hegazy, and T. M. El Sherbini, 2006. Measurement of electron density utilizing the Ha-line from laser produced plasma in air. Spectrochimica Acta PartB 61 (5):532-39.

Fujimoto, T., and R. W. P. McWhirter. 1990. Validity criteria for local thermodynamic equilibrium in plasma spectroscopy. Physical Review A 42 (11):6588-601.

Feng, Y., J. Yang, J. Fan, G. Yao, X. Ji, X. Zhang, X. Zheng, and Z. Cui. 2010. Investigation of laser-induced breakdown spectroscopy of a liquid jet. Applied Optics 49 (13):C70-C74.

Faye, C. B., T. Amodeo, E. Fréjafon, N. Delepine-Gilon, and C. Dutouquet. 2014. Sampling considerations when analyzing micrometric-sized particles in a liquid jet using laser induced breakdown spectroscopy. Spectrochimica Acta B91:5-11.

Griem, H. R. 1964. Plasma spectroscopy. New York: McGraw-Hill.

Griem, H. R. 1974. Spectral line broadening by plasmas. New York: Academic Press Inc.

Haisch, C., J. Liermann, U. Panne, and R. Niessner. 1997. Characterization of colloidal particles by laser-induced plasma spectroscopy (LIPS). Analytica Chimica Acta 346 (1):23-35.

Huang, J.-S., C.-B. Ke, L.-S. Huang, and K.-C. Lin. 2002. The correlation between ion production and emission intensity in the laser-induced breakdown spectroscopy of liquid droplets. Spectrochimica Acta Part B 57 (1):35-48.

Huang, J.-S., H.-T. Liu, and K.-C. Lin, 2007. Laser-induced breakdown spectroscopy in analysis of $\mathrm{Al}^{3+}$ liquid droplets: On-line preconcentration by use of flow-injection manifold. Analytica Chimica Acta 581 (2):303-308. 
Henden, E., Y. İşlek, M. Kavas, N. Aksuner, O. Yayayürük, T. D. Çiftçi, and R. İlktaç. 2011. A study of mechanism of nickel interferences in hydride generation atomic absorption spectrometric determination of arsenic and antimony. Spectrochimica Acta Part B 66 (11-12):793-98.

Janzen, C., R. Fleige, R. Noll, H. Schwenke, W. Lahmann, J. Knoth, P. Beaven, E. Jantzen, A. Oest, and P. Koke. 2005. Analysis of small droplets with a new detector for liquid chromatography based on laser-induced breakdown spectroscopy. Spectrochimica Acta Part B 60 (7):993-1001.

Knight, A. K., N. L. Scherbarth, D. A. Cremers, and M. J. Ferris. 2000. Characterization of laserinduced breakdown spectroscopy (LIBS) for application to space exploration. Applied Spectroscopy 54 (3):331-40.

Kumar, A., F. Y. Yueh, and J. P. Singh. 2003. Double-pulse laser-induced breakdown spectroscopy with liquid jets of different thicknesses. Applied Optics 42 (30):6047-6051.

Koch, S., W. Garen, W. Neu, and R. Reuter. 2006. Resonance fluorescence spectroscopy in laserinduced cavitation bubbles. Analytical and Bioanalytical Chemistry 385 (2):312-15.

Kumar, A. R. and P. Riyazuddin. 2010. Chemical interferences in hydride-generation atomic spectrometry. TrAC - Trends in Analytical Chemistry 29 (2):166-76.

Lee, D.-H., S.-C. Han, T.-H. Kim, and J.-I. Yun. 2011. Highly sensitive analysis of boron and lithium in aqueous solution using dual-pulse laser-induced breakdown spectroscopy. Analytical Chemistry 83 (24):9456-61.

Miziolek, A. W., V. Palleschi, and I. Schechter. 2006. Laser induced breakdown spectroscopy. New York: Cambridge University Press.

Pohl, P. and W. Zyrnicki. 2002. Study of chemical and spectral interferences in the simultaneous determination of $\mathrm{As}, \mathrm{Bi}, \mathrm{Sb}$, Se and $\mathrm{Sn}$ by hydride generation inductively coupled plasma atomic emission spectrometry. Analytica Chimica Acta 468 (1):71-79.

Pearman, W., J. Scaffidi, and S. M. Angel. 2003. Dual-pulse laser-induced breakdown spectroscopy in bulk aqueous solution with an orthogonal beam geometry. Applied Optics 42 (30):6085-93.

Pohl, P. 2004. Hydride generation-recent advances in atomic emission spectrometry. TrAC - Trends in Analytical Chemistry 23 (2):87-101.

Piscitelli, S. V., M. Martínez L, A. Fernández C, J. González, X. Mao, and R. Russo. 2009. Double pulse laser induced breakdown spectroscopy: experimental study of lead emission intensity dependence on the wavelengths and sample matrix. Spectrochimica Acta Part B 64 (2):147-54.

Radziemski, L. J., T. R. Loree, D. A. Cremers, and N. M. Hoffman. 1983. Time-resolved laser-induced breakdown spectrometry of aerosols. Analytical Chemistry 55 (8):1246-52.

Rai, V. N., F. Y. Yueh, and J. P. Singh. 2008. Time-dependent single and double pulse laser-induced breakdown spectroscopy of chromium in liquid. Applied Optics 47 (31):G21-G29.

Rifai, K., S. Laville, F. Vidal, M. Sabsabi, and M. Chaker. 2012. Quantitative analysis of metallic traces in water-based liquids by UV-IR double-pulse laser-induced breakdown spectroscopy. Journal of Analytical Atomic Spectrometry 27 (2):276-83.

Sabsabi, M. and P. Cielo 1995. Quantitative analysis of aluminum alloys by laser-induced breakdown spectroscopy and plasma characterization. Applied Spectroscopy 49 (4):499-507.

Singh, J. P., H. Zhang, F.-Y. Yueh, and K. P. Carney. 1996. Investigation of the effects of atmospheric conditions on the quantification of metal hydrides using laser-induced breakdown spectroscopy. Applied Spectroscopy 50 (6):764-73.

Samek, O., D. C. Beddows, J. Kaiser, S. V. Kukhlevsky, M. Liska, H. H. Telle, and J. Young 2000. Application of laser-induced breakdown spectroscopy to in situ analysis of liquid samples. Optical Engineering 39 (8):2248-62.

Sarkar, A., S. K. Aggarwal, K. Sasibhusan and D. Alamelu. 2010. Determination of sub-ppm levels of boron in ground water samples by laser induced breakdown spectroscopy. Microchimica Acta $168(1-2): 65-69$.

Simeonsson, J. and L. Williamson. 2011. Characterization of laser induced breakdown plasmas used for measurements of arsenic, antimony and selenium hydrides. Spectrochimica Acta Part B 66 (9):754-60.

Unnikrishnan, V., R. Nayak, K. Aithal, V. Kartha, C. Santhosh, G. Gupta, and B. Suri, 2013. Analysis of trace elements in complex matrices (soil) by laser induced breakdown spectroscopy (LIBS). Analytical Methods 5 (5):1294-300. 
Ünal, S. and Ş. Yalçın. 2010. Development of a continuous flow hydride generation laser-induced breakdown spectroscopic system: Determination of tin in aqueous environments. Spectrochimica Acta Part B 65 (8):750-57.

Vrenegor, J., R. Noll, and V. Sturm. 2005. Investigation of matrix effects in laser-induced breakdown spectroscopy plasmas of high-alloy steel for matrix and minor elements. Spectrochimica Acta Part B 60 (7):1083-91.

Yeşiller, S. Ü. and Ş. Yalçın. 2013. Optimization of chemical and instrumental parameters in hydride generation laser-induced breakdown spectrometry for the determination of arsenic, antimony, lead and germanium in aqueous samples. Analytica Chimica Acta 770:7-17.

Zheng, C., R. E. Sturgeon, and X. Hou. 2010. Thin film hydride generation: Determination of ultra-trace copper by flow injection in situ hydride trapping graphite furnace AAS. Journal of Analytical Atomic Spectrometry 25 (7):1159-65. 